This item was submitted to Loughborough's Research Repository by the author.

Items in Figshare are protected by copyright, with all rights reserved, unless otherwise indicated.

\title{
Early sport specialization and intensive training in adolescent female athletes: Risks and recommendations
}

PLEASE CITE THE PUBLISHED VERSION

https://doi.org/10.1519/SSC.0000000000000315

\section{PUBLISHER}

Lippincott Williams \& Wilkins $@$ National Strength and Conditioning Association

\section{VERSION}

AM (Accepted Manuscript)

\section{PUBLISHER STATEMENT}

This work is made available according to the conditions of the Creative Commons Attribution-NonCommercialNoDerivatives 4.0 International (CC BY-NC-ND 4.0) licence. Full details of this licence are available at: https://creativecommons.org/licenses/by-nc-nd/4.0/

\section{LICENCE}

CC BY-NC-ND 4.0

\section{REPOSITORY RECORD}

Blagrove, Richard, Georgie Bruinvels, and Paul Read. 2019. "Early Sport Specialization and Intensive Training in Adolescent Female Athletes: Risks and Recommendations". figshare. https://hdl.handle.net/2134/38156. 
Early sport-specialization and intensive training in adolescent female athletes: risks and recommendations

Richard C. Blagrove ${ }^{1,2}$ BSc. (Hons) MSc., ASCC, CSCS

\section{Georgie Bruinvels ${ }^{3,5,6}$ BSc (Hons)}

Paul Read ${ }^{4,5}$ PhD, ASCC, CSCS*D

${ }^{1}$ School of Health Sciences, Birmingham City University, United Kingdom; ${ }^{2}$ Division of Sport, Exercise and Rehabilitation, Northumbria University, United Kingdom; ${ }^{3}$ Division of Surgery and Interventional Science, University College London, United Kingdom; ${ }^{4}$ Department of Sports Medicine, Aspetar, Qatar Orthopaedic and Sports Medicine Hospital, Qatar; ${ }^{5}$ School of Sport, Health and Applied Science, St Mary's University, United Kingdom; ${ }^{6}$ Orreco Ltd, Institute of Technology, Sligo, Ireland

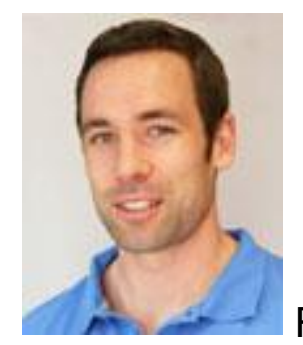

Richard Blagrove is a Strength and Conditioning Coach and Course Leader for the BSc Sport and Exercise Science at Birmingham City University, UK.

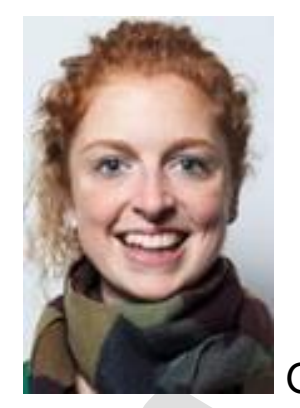

Georgie Bruinvels is a PhD student at University College London and a Research Scientist and Exercise Physiologist at St Mary's University and Orreco.

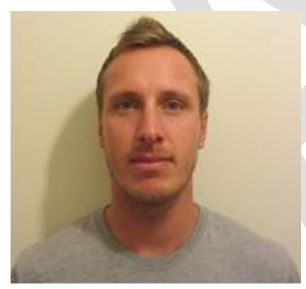

Paul Read is a Strength and Conditioning Coach and Clinical Researcher at Aspetar Orthopedic and Sports Medicine Hospital, Doha, Qatar. 


\title{
Early sport-specialization and intensive training in adolescent female athletes: risks and recommendations
}

\begin{abstract}
Early sport-specialization is often characterized by intensive training, and is becoming increasingly common. Adolescent female athletes, who train excessively and adopt poor diets, are at risk of the female athlete triad, overuse injury, mental health issues, and overtraining. The occurrence of one or more of these issues can lead to early-retirement from sport, and may have serious long-term health consequences. Practitioners working with young females are recommended to adopt a holistic approach to the development of their athletes, including participation in a diverse range of sports, monitoring health status, and ensuring caloric intake meets the demands of the athlete's lifestyle.
\end{abstract}

KEY WORDS: female athlete triad, long-term athlete development, pediatrics

\section{INTRODUCTION}

Puberty represents a key period of development in young athletes where a significant alteration in hormonal status causes rapid physical growth, development of sexual characteristics, and attainment of reproductive capacity (57). Young athletes are encouraged to participate in a diverse range of sports and physical activities during childhood, and maintain this practice during early-adolescence, which is thought to help support their physical, social, cognitive, and emotional development (51). Recently, there has been growing concern that many young female athletes are focusing on single sport participation at a young age (13). Intensive training and sub-optimal dietary intake during adolescence is likely to negate many of the benefits associated with sports participation, and instead cause a number of potentially serious health issues, including the female athlete triad, overuse injury, and burnout $(10,21$, 62). The purpose of this article is to examine these potential risks, and provide practical recommendations to reduce the likelihood of this scenario from developing; thus, helping talented young female athletes achieve their full potential.

\section{EARLY SPORT-SPECIALIZATION}

Contemporary models of long-term athlete development suggest adolescents should avoid training routines that focus on intensive training in a single sport (for $>8$ months per year), or a total weekly training volume which exceeds the athletes age in years, until late adolescence $(19,49)$. Whilst some degree of sport-specialization is necessary during adolescence to reach elite status, the timing of single sport-specialization is more controversial. Governing bodies of most professional sports have talent identification and development systems that aim to identify, and subsequently nurture the most gifted young athletes using only the sport $(78,80)$. However, evidence across a range of sports shows elite senior athletes tend to specialize at a later age, and participate in a diverse range of sports during their childhood $(19,65)$. As a result, the level of focussed physical training and competition that young athletes are exposed to early in their careers is often excessive. Conversely, young athletes who adopt an early- 
diversification, late-specialization approach to their development have fewer injuries, are at less risk of overtraining, and play sports longer than those who specialize in one sport before puberty $(13,20)$.

\section{THE FEMALE ATHLETE TRIAD}

Early sport-specialization has been identified as an independent risk factor for the female athlete triad $(89,96)$. The female athlete triad describes three inter-related components of health: energy availability, menstrual cycle function, and bone mineral density (BMD) status, which each exist on a continuum from optimal health to disease. When intensive training regimens are combined with insufficient energy intake and recovery to support the exercise being undertaken, young female athletes are at risk of developing one, two, or all three components of the female athlete triad (96). Female athletes who specialize in disciplines that demand high levels of leanness and endurance (such as gymnastics, dance, distance running and figure skating) are particularly vulnerable $(71,96)$. It is beyond the scope of this paper to provide a detailed account of the prevalence, tools for diagnosis and pathophysiology associated with each condition, therefore the reader is referred to more comprehensive reports $(41,71,96)$. A summary of the main warning signs for various stages of each continuum, and risk factors associated with the triad is shown in Figure 1.

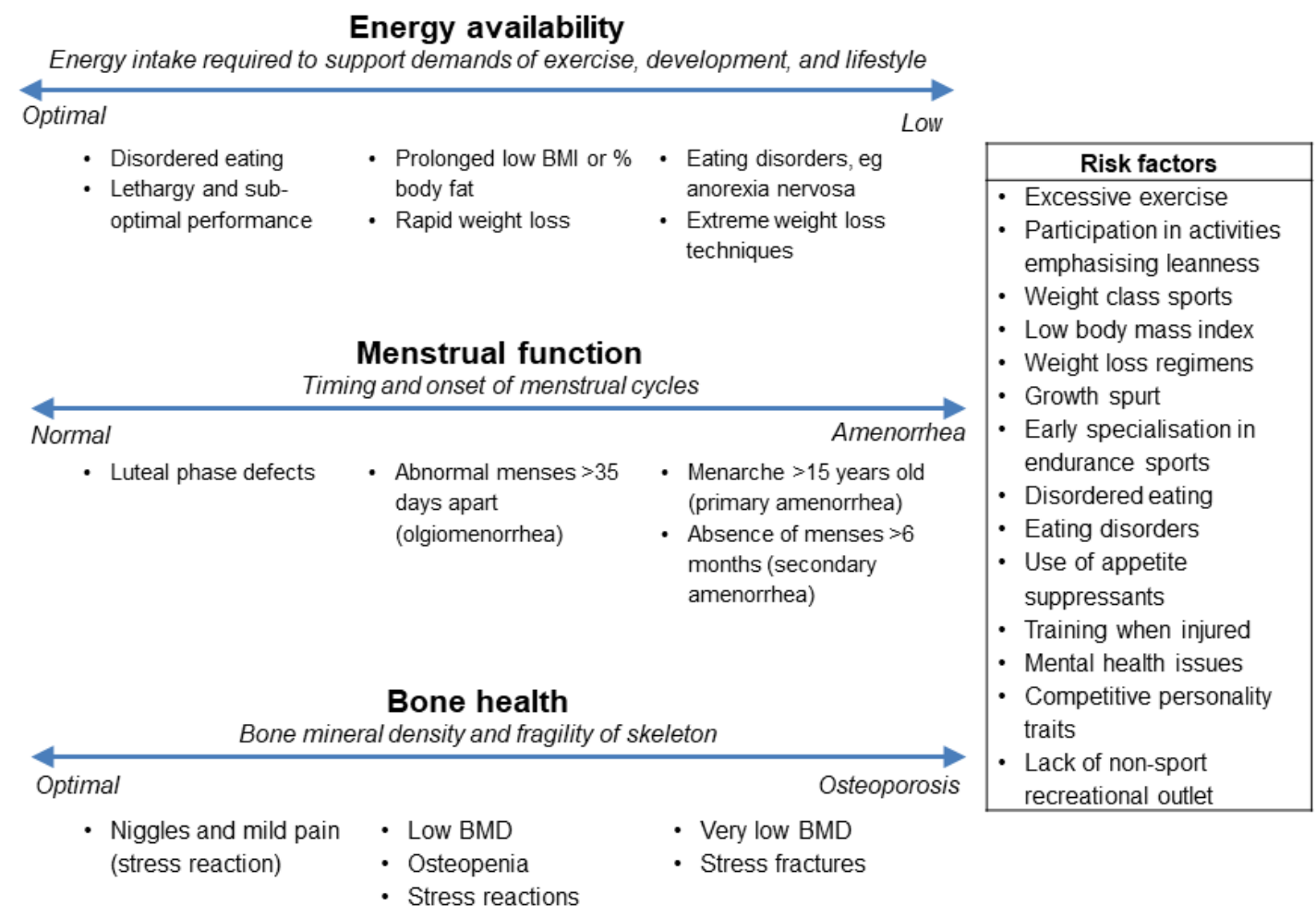

Figure 1. Definition, signs and risk factors for the female athlete triad. BMD = Bone mineral density. 
Insufficient energy intake to support the demands of the athlete's lifestyle is the primary driver of the triad, as a negative energy balance disturbs the metabolic and hormonal regulation of menstrual function, and compromises maintenance and development of bone (41). Recent literature has suggested the triad should be viewed more as a syndrome resulting from energy deficiency, which leads to a host of physiological complications including menstrual dysfunction, poor bone health, weak immunity and mental health issues (67).

Studies indicate that only $1-1.2 \%$ of high school female athletes suffer from all three components of the triad, however the prevalence of one component has been reported to be between $16-54 \%$ in young athletes $(40,72)$. Comparisons against occurrence of the triad in adult athletes is problematic due to differences in data collection techniques and definitions, however it is thought incidence is lower in adolescents compared to elite and collegiate level athletes $(72,96)$. Nevertheless, because adolescence is a critical period for accruing bone mass, there is a need to understand the long-term risks associated with triad disorders at a young age, and provide guidance and recommendations to coaches and parents.

\section{RISKS ASSOCIATED WITH INTENSIVE TRAINING}

\section{GROWTH AND PUBERTAL DEVELOPMENT}

Growth and pubertal development are influenced by genetic and environmental factors, including physical activity and lifestyle stresses $(88,94)$. Moderate amounts of exercise are thought to have a positive effect on skeletal development during growth (43), however, it has been speculated that intensive regimens of exercise during adolescence may affect growth rate and final stature $(57,61)$.

In female gymnasts undertaking intense training ( $>15$ hours per week), cross-sectional data shows skeletal maturation and pubertal development to occur later, compared to recreational gymnasts (24) and untrained controls $(15,29,75,91)$. Similarly, figure skaters, divers, and ballet dancers tend to have shorter statures during childhood and early adolescence (58), whereas female athletes in volleyball, diving, distance running, and basketball demonstrate growth rates similar to non-athletic children (58). Excessive training may exert a causative influence on growth rate via a negative energy balance, which alters the concentrations of hormones (samatomedin $\mathrm{C}$, growth hormone, estrogen) due to a delayed onset of puberty (28).

Nevertheless, the rate of growth and maturation of successful young female athletes engaged in intensive training from a young age falls largely within the range of normal variability (60). The absence of a pubertal growth spurt in elite young female athletes is subsequently compensated for by accelerated growth in late adolescence or early adulthood $(30,58)$. Moreover, there is also evidence showing that young athletes who are shorter in adolescence also have shorter parents (8).

It is therefore likely that these young females naturally exhibit the physical characteristics required to succeed in sports, as they demonstrate a similar pattern of growth and maturation to short and late-maturing non-athletes (60). Indeed, cross-sectional data from elite female adolescent athletes indicate that body composition and anthropometric variables discriminate participation in certain sports $(39,46)$. Distance runners for example are typically lighter and 
have lower body fat than swimmers and other track and field athletes (39). The physically under-developed appearance of many elite adolescent female distance runners suggests they may excel due to their physically immature musculoskeletal structure. A narrower pelvic girdle, lower body fat percentage, and lighter weight, are all likely to provide a benefit to physiological qualities such as maximal oxygen uptake and running economy (2).

\section{MENSTRUAL CYCLE}

Physical exercise is beneficial for female reproductive function and can improve menstrual cyclicity, ovulation, and fertility (74). Equally, menstrual function is highly sensitive to physiological stress; therefore, female athletes engaged in intensive physical training programs are susceptible to developing menstrual cycle dysfunctions. High amounts of stress cause a negative energy balance, first affecting the female reproductive system as it is nonvital for survival (41). Energy deficiency results in a hypometabolic state causing a reduction in estrogen, which reduces pulsatility of the gonadotropin-releasing hormone (57). The effect is manifested as amenorrhea (primary or secondary) or oligomenorrhea (41).

Primary amenorrhea is the absence of menses at age 15 despite normal growth and signs of secondary sexual characteristics (41). A lack of menarche three years after initial development of secondary sexual characteristics, or no sign of these characteristics by the age of 14 , is also deemed abnormal (96). Secondary amenorrhea is the absence of menses for more than three consecutive months or six months in females who have previously had regular menses. Oligomenorrhea is defined as menstrual cycles that occur $>35$ days apart (41). A luteal phase $<11$ days in length is known as a luteal phase deficiency, but is generally symptom free, making diagnosis problematic (96).

For active girls, the timing of menarche relative to peak height velocity is generally similar to that of non-athletic girls (27). However, there is a high prevalence of menstrual dysfunctions during adolescence, particularly in athletes involved in intensive sports training (40). Primary amenorrhea affects $1-6 \%$ of adolescent athletes, typically in those who strive to maintain a high level of leanness for their sport $(5,72,73)$. Amenorrhea (primary and secondary) has also been reported in $24 \%$ of female high school athletes from eight different sports (72). Oligomenorrhea is also common (5-18\% of adolescent athletes), but is difficult to diagnose in adolescents, as eumenorrhea (normal menses) is typically not established until early adulthood (41).

Evidence suggests that a cause-effect relationship exists between energy availability and menstrual dysfunction, rather than exercise or body weight exerting an independent influence $(54,57)$. Indeed, in monkeys, it has been shown that amenorrhea can be reversed by increasing energy intake without altering exercise training (97). Typically adolescent athletes who present with amenorrhea possess significantly lower BMD compared to eumenorrheic young athletes and non-athletic controls (5). Athletes with menstrual cycle abnormalities are also three times more likely to sustain a musculoskeletal injury compared to eumenorrheic adolescents $(6,77)$. A relationship between older menarcheal age and stress fractures has also been reported (10). Although the association between menstrual disturbances and injury is not causative, a low energy state alters the profile of thyroid and stress hormones, which directly affects bone metabolism and the health of muscle and connective tissue $(47,52)$. The 
impact of menstrual dysfunction upon performance is less certain; however, performance impairment has been shown in swimmers displaying ovarian suppression (92).

Use of the oral contraceptive (estrogen) pill (OCP) has been suggested for treatment of menstrual dysfunction in young women $(41,48)$; however, their use remains questionable in young athletic females (85). The effects of the OCP on BMD have provided conflicting results $(17,64,95)$. Although monthly menstrual cycles appear to return with the administration of the $\mathrm{OCP}$, this provides a false sense of normality for athletes who fail to address low energy availability (96). The OCP provides an artificial hormonal environment that supresses markers of bone formation and absorption, and thus may actually be harmful to overall bone health $(17,93)$.

The current evidence indicates that intensive physical training per se is unlikely to be a causative factor for menstrual irregularities in young females (53). However, some young females might find themselves unintentionally in a chronic hypometabolic state due to the energy expenditure of exercise, combined with pressures to attain a lean physique for their sport.

\section{BONE MINERAL ACCRUAL}

Weight-bearing exercise has a positive impact on bone health in children and adolescents (26, 55). Similarly, young athletes (age 12-16 years) involved in high impact sports have been shown to possess higher BMD compared to participants from low impact sports and nonathletes of the same age $(1,70)$. Skeletal adaptation to stress is slow; thus, prepubertal and pubertal years represent a highly sensitive period for gains in bone mass (7). Environmental factors, which negatively impact upon the acquisition of bone during this period, are likely to have harmful consequences. In late-adolescence, approximately $90 \%$ of bone mass has been accrued (84). Worryingly, adolescent female athletes who fail to maximise bone mass accrual during their development years are unlikely to compensate in later years, even with reduced levels of physical activity, improved energy availability and resumption of regular menses (9, 22). A permanently lower BMD compared to their genetic potential therefore increases the risk of osteoporosis and sustaining fractures from falls in later life (9). It is therefore essential that appropriate exercise interventions are adopted and eating habits are closely monitored during these crucial years to maximize bone development. When volumes of repetitive loading or intensities of loading are excessive, the bone remodelling process cannot keep pace, eventually resulting in stress fractures (85). Initially, microfracture to trabecular bone will occur (termed 'stress reaction') and cause pain and discomfort at the site (see Figure 1). Continued exposure to repetitive stress will eventually weaken the cortex of the bone and cause a stress fracture (25). Stress fractures are most common in sports which demand repetitive forceful impacts, such as distance running (3). Early sport-specialization, changes in running surface and rapid increases of training frequency, duration and intensity are all extrinsic factors associated with stress fractures in distance runners (36).

The negative effects of intensive training routines are compounded by inadequate energy availability caused by a poor diet, excessive caloric expenditure or a combination of both (85). In particular, a negative energy balance in females causes a hypoestrogenic state as the hypothalamic-pituitary axis is impaired (41). This subsequently increases osteoclastic activity 
and thus attenuates bone development. Low energy availability also impacts bone formation directly, via the suppression of triodothyronine, somatomedin $C$ and insulin (85). Menstrual cycle abnormalities are therefore a major risk factor for low BMD in adolescent athletes. Amenorrheic athletes typically have a $10 \%$ lower BMD compared to eumenorrheic athletes, and are at greater risk of developing stress fractures (85). A low BMD has been associated with disordered eating in eumenorrheic runners (17); however, gymnasts have been shown to possess high BMD despite a high prevalence of menstrual dysfunction (82). Therefore, physical activity and energy availability appear to exert independent effects on bone status.

\section{OVERUSE INJURY}

The causes of overuse injury are multifaceted; however, training volume, early-specialization, and maturation status have all been identified as risk factors (68). Talented young athletes who demonstrate superior physical performance are likely to be pushed into intensive singlesport training programs at a young age (68). High volumes of training are generally associated with a higher risk of injury in adolescent athletes $(23,56)$, which can cause depression and loss of training time $(13,20)$. The likelihood of suffering an overuse injury is also higher for young athletes who have specialized in a single sport, as opposed to those who participate in a range of sports $(35,42)$. It has been suggested that athletes should not participate in more hours of organized sport than their age in years (or more training than 16 hours per week), as greater levels of participation substantially increase injury risk (42).

During adolescence, the connective tissues, muscles, and bones develop in a non-linear manner, and are not fully developed until late adolescence (58). Following the adolescent growth spurt (typically 11-12 years old in females), there is a lag in the development of the neuromuscular system, which effects strength and coordination in girls to a greater extent than boys (38). Repetitive loading of tissues with insufficient recovery or inadequate nutrition is therefore likely to increase the risk of injury. For early maturing females, rapid changes in stature, strength, and limb lengths may exacerbate risk of injury when combined with intensive regimens of physical work (4). Non-linear musculoskeletal development through maturation can affect biomechanics in female athletes, which can cause poor movement patterns and inappropriate attenuation of forces (37). Participating in a variety of sports until lateadolescence, which facilitates development of a range of motor skills, and provides exposure to variety of loading patterns is likely to reduce the risk of overuse type injuries associated with early sports-specialization (69).

Injury is often cited as a reason for quitting sport during adolescent years (14), and is a leading cause of the high-drop rates seen during late-adolescence and early adulthood in those who previously competed at a high level (4). Fear of injury or re-injury can also affect engagement with physical activity long-term $(44,86)$, potentially leading to health issues in adulthood.

\section{MENTAL HEALTH AND BURNOUT}

A decision to specialize and compete year-round in only one sport brings with it an inevitable pressure to achieve pre-determined goals and continually progress. This is often further compounded by the pressures placed on young athletes by coaches and parents (32). Chronic exposures to highly stressful and professionalized sporting environments at a young age are 
unlikely to be effective at nurturing talented performers into future elite athletes $(33,65)$. It has been shown that intrinsic motivation factors, such as enjoyment of practise are most important in retaining young athletes, and achieving long-term ambitions $(45,87)$.

Psychological challenges during an athlete's development provides a positive response to promote long term attainment (18). However, excessive psychological overload resulting from unrealistic expectations on what a young female can physically achieve can be detrimental, causing depression, anxiety, and ultimately burnout (11). Adolescent girls in particular are prone to depression (90); therefore creating a high pressure training environment may exacerbate this risk.

Burnout refers to the negative psychosocial factors that influence under-performance in athlete, but is closely linked to overtraining and risk of (re-) injury (12). It has been suggested that burnout is a leading cause of early retirement from sport in those who have experienced intense training from a young age (68). From a psychological perspective, studies have reported young athletes who suffered burnout, and retired from sport prematurely, perceived that they lacked of control over their lives, had little input into decision-making, and regularly had low levels of motivation to practice $(14,31)$.

Young females competing in leanness and weight class sports are at high risk of developing patterns of disordered eating, which is also associated with psychological problems (41). Moreover, adolescent females who display signs of eating disorders have an increased likelihood of displaying psychological problems including low self-esteem, anxiety, and depression (71). Athletes who suffer from an eating disorder are also $5 \%$ more likely to attempt suicide than athletes without an eating disorder (71).

\section{OVERTRAINING AND CARDIAC CONCERNS}

Overtraining is caused by an accumulation of training and non-training stress, which results in chronic under-performance, taking several weeks or months to recover from (63). The prevalence of overtraining syndrome in young athletes is concerning. Several investigations have shown approximately one-third of competitive female (13-18 years) athletes across a range of sports in various countries had suffered from overtraining or burnout at least once $(34,62,76)$. In a study from the UK, the incidence of overtraining was also higher in female athletes age 11-18 years compared to male athletes (62).

Physiological responses to overreaching and overtraining in young female athletes are similar to those seen in adult athletes but are highly variable (98). Overtraining is characterised by a plethora of signs and symptoms, which are derived from several different physiological systems including: increased perception of effort during exercise, frequent upper respiratory tract infections (URI), sleep disruption, excessive muscular fatigue, and a loss of appetite. Many of these symptoms, are also likely to impact other aspects of a young athletes lifestyle, including their academic work and social life (81).

There have also been concerns put forward that cardiac disturbances (arrhythmias) and changes in electrocardiogram traces can result from a state of overtraining (63); however there is currently no evidence to support this notion in young female athletes. It has also been 
theorised that intensive athletic training in pre-pubertal children can lead to unique cardiac hypertrophy, which may predispose athletes to arrhythmias that can potentially be fatal (83). However, it is likely that any structural adaptation to cardiac muscle at a young age is relatively trivial and unrelated to a pathological condition (83), although further longitudinal research is required (11).

\section{BREADTH OF EXPERIENCE AND SKILL}

Early sport-specialization, particularly in activities involving repetitive actions, limits the acquisition of a wide range of motor skills. This may seem beneficial in the short-term for the child athlete aspiring to greatness in their chosen sport; however, it drastically limits opportunities to participate in other sports. Equally, a reduction in motor skills could adversely affect lifelong participation in physical activity as the athlete feels limited to the sport they have always competed in (66). It has been hypothesized that these lost opportunities for development of a diverse range of sports skills, may in part contribute to the current high levels of physical inactivity and obesity in adulthood (66).

From a psychosocial perspective, concern has also been raised that placing high training demands on a young athlete limits their opportunity to develop a normal, multifaceted identity (16). Young athletes who specialize in a single sport report they become consumed by their training and feel a sense of isolation (16). When fitted around school timetables, intensive training programmes severely restrict the time young athletes can dedicate to other activities. Therefore, young athletes develop a unidimensional identity and feel defined by their sport, which can lead to stress and anxiety if they fail to reach their goals (98).

There is a growing body of evidence indicating early sport-specialization predisposes young athletes to overuse injury (68). Diverse sports participation not only reduces the volume of repetitive technical skills, but exposes the neuromuscular system to a range of different mechanical and physiological stresses, which is likely to improve capacity and robustness, thus lowering long-term injury risk (35). In addition, a well-rounded approach to athlete development should involve integrated neuromuscular training that aims to teach a wide range of fundamental motor patterns which underpin effective movement in sports skills $(11,69)$.

\section{General recommendations}

Provide education and guidance to young female athletes and their parents

An inter-disciplinary approach should be adopted to the management of a young female athletes health, fitness and well-being

Young athletes should be given the opportunity to make their own decisions concerning their participation in sport

A balanced lifestyle should be promoted, which includes a variety of social, academic, sports and leisure activities

\section{Sport-specialization recommendations}

Athletes should be considered as individuals to account for differences in biological maturation 


\begin{tabular}{|l|}
\hline Children should avoid single-sport specialization before age 13 \\
\hline Highly specialized training should not occur before late-adolescence ( $>15$ years) \\
\hline $\begin{array}{l}\text { The sporting environment should aim to develop physical as well as psychosocial } \\
\text { attributes in the athlete. }\end{array}$ \\
\hline Avoidance of the female athlete triad \\
\hline $\begin{array}{l}\text { Regular screening for components of the triad should be carried out by a qualified } \\
\text { professional }\end{array}$ \\
\hline Optimal energy intake is the cornerstone of prevention methods \\
\hline Coaches/parents should be vigilant to patterns of disordered eating \\
\hline The OCP should be avoided as a first line of treatment for menstrual dysfunction \\
\hline Physical training recommendations \\
\hline Provide regular opportunities for free, fun and unstructured play \\
\hline $\begin{array}{l}\text { Total volume of weekly training should not exceed age in years (or } 16 \text { hours per } \\
\text { week) }\end{array}$ \\
\hline $\begin{array}{l}\text { Integrate appropriate strength and conditioning activities } 2-3 \text { times per week that } \\
\text { focuses on the development of fundamental motor skills and physical qualities }\end{array}$ \\
\hline Regular participation in weight-bearing activities should be included \\
\hline $\begin{array}{l}\text { Training and competition schedules should be carefully monitored to ensure } \\
\text { workload is appropriate for various stages of an athlete's development }\end{array}$ \\
\hline Following sport-specialization, include 1-2 days off specific sport training per week \\
\hline
\end{tabular}

Table 1. Recommendations to minimize the risks associated with intensive and specialized sports training in adolescent females. OCP $=$ oral contraceptive pill.

\section{RECOMMENDATIONS FOR MINIMIZING RISKS}

While some sports necessitate early sport-specialization due to the timing of peak physical performance relative to maturity (59), given the risks and associated health concerns of females following intensive training regimes at a young age, there is a need to re-address the approach to long-term physical preparation of athletes in specific sports. Although there is little evidence that growth and maturation is affected long-term in athletes from these sports, there is a high prevalence of the female athlete triad, overuse injury, and overtraining.

Table 1 provides a list of the key recommendations for adolescent female athletes and their parents to avoid the risks associated with intensive training programmes, and optimize opportunities long-term. Where possible, an interdisciplinary approach should be adopted to the management of a young female athlete's development, which includes active participation from the athlete themselves. A holistic approach is also thought to be most effective for preventing and treating the female athlete triad and overtraining syndrome $(96,98)$. Coaches should provide education and guidance to young female athletes and their parents concerning: appropriate levels of physical training at each stage of maturation, self-management strategies, and adequate nutrition. In particular, coaches and parents should also be vigilant to recurrent URI, disrupted sleep patterns, changes in mood, weight loss, obsessive behaviours and prolonged fatigue (98). 
To avoid sport-specialization at an inappropriate time, each athlete should be considered individually, as the tempo and timing of biological maturation is unique to each athlete (11). Around age 13 years, children should have opportunity to specialize in their favourite sport, or continue participating in a diverse range (19). Once athletes begin to specialize, regular periods ( 1 in every 3 months) where they revert back to a diverse range of activities should be included (13). Highly specialized training for only one sport should occur around late adolescence, after the age of 15 (19). A sporting environment that develops psychosocial attributes should also be created. Athletes should be taught to be respectful and co-operative whilst having the resilience and adaptability to self-regulate and cope in increasingly stressful situations as they mature (11).

Importantly, young female athletes engaged in intensive sports training should be screened regularly for components of the female athlete triad by a qualified professional (96). Optimal energy intake is crucial for minimizing the risk of developing the female athlete triad. Young female athletes should therefore be provided with dietary intake guidance, and advised that menstrual dysfunction is a sign of inadequate energy intake. Parents and practitioners providing support to young females should be vigilant to patterns of disordered eating to avoid menstrual cycle abnormities or osteoporosis. More importantly, young athletes who attempt to utilize specific dietary strategies to reduce their body fat should be monitored closely, as behaviour of this nature has been linked to a psychological profile which indicates an eating disorder (79).

For pre-pubescent females, parents and coaches should seek to provide opportunities for free, fun, and unstructured play, which encompasses development of a diverse range of sports and motor skills (69). Providing a variety of sports equipment in a safe supervised space and allowing children to invent their own versions of games, which aren't bound by traditional rules, is one example of how this can be implemented. All young female athletes should include regular strength and conditioning activities into their training routine (50). This should consist of a wide variety of physical training activities (e.g. resistance training, agility, sprinting, plyometrics, trunk, and postural exercises) that focus on the development of fundamental motor skills and components of fitness $(49,69)$. Weight-bearing activities such as sprinting, jumping, and agility games are highly effective for bone mineral accrual so should be included in all exercise programmes. The volume of sport participation a young female should undertake each week (in hours) should not exceed the athletes age (in years) or 16 hours per week of intense exercise (69). For athletes involved in repetitive impact sports in particular, effective management of training frequency, intensity, or duration is crucial to avoid stress fractures. Following sport-specialization in late-adolescence, it is recommended that athletes take 1-2 days off specific sport training per week (13).

\section{CONCLUSION}

Adolescence is a crucial period of growth and maturation but also an important period to develop healthy lifestyle habits, which includes participation in a diverse range of sports and eating well. Intensive training routines, which are often the hallmark of early sportspecialization programs, can cause a number of significant health concerns for young female athletes, particularly those who participate in sports which demand low levels of body weight. 
Coaches supporting young female athletes have an important role to play in preventing and detecting the female athlete triad, and managing long-term athlete development.

\section{REFERENCES}

1. Ackerman, KE, and Misra, M. Bone health in adolescent athletes with a focus on the female athlete triad. Phys Sportsmed 39:131-141, 2011.

2. Anderson, T. Biomechanics and running economy. Sports Med 22:76-89, 1996.

3. Arendt, E, Agel, J, Heikes, C, and Griffiths, H. Stress injuries to bone in college athletes: a retrospective review of experience at a single institution. Am J Sports Med 31:959-968, 2003.

4. Bahr, R. Demise of the fittest: are we destroying our biggest talents? Br J Sport Med 48:1265-1267, 2014.

5. Barrack, MT, Rauh, MJ, and Nichols, JF. Prevalence of and traits associated with low BMD among female adolescent runners. Med Sci Sports Exerc 40:2015-2021, 2008.

6. Barrack, MT, Gibbs, JC, De Souza, MJ, Williams, NI, Nichols, JF, Rauh, MJ, and Nattiv, A. Higher incidence of bone stress injuries with increasing female athlete triad-related risk factors: a prospective multisite study of exercising girls and women. Am J Sports Med 42:949-958, 2014.

7. Bass, SL. The prepubertal years-A unique opportune stage of growth when the skeleton is most responsive to exercise? Sports Med 30:73-78, 2000.

8. Baxter-Jones, AD, Helms, P, Maffulli, N, Baines-Preece, JC, and Preece, M. Growth and development of male gymnasts, swimmers, soccer and tennis players: a longitudinal study. Ann Hum Biol 22:381-394, 1995.

9. Baxter-Jones, AD, Faulkner, RA, Forwood, MR, Mirwald, RL, and Bailey, DA. Bone mineral accrual from 8 to 30 years of age: an estimation of peak bone mass. $J$ Bone Miner Res 26:1729-1739, 2011.

10. Bennell, KL, Malcolm, SA, Thomas, SA, Reid, SJ, Brukner, PD, Ebeling, PR, and Wark, JD. Risk factors for stress fractures in track and field athletes. A twelve-month prospective study. Am J Sports Med 24:810-818, 1996.

11. Bergeron, MF, Mountjoy, M, Armstrong, N, Chia, M, Côté, J, Emery, CA, Faigenbaum, A, Hall, Jr G, Kriemler, S, Léglise, M, Malina, RM, Pensgaard, AM, Sanchez, A, Soligard, T, Sundgot-Borgen, J, van Mechelen, W, Weissensteiner, JR, and Engebretsen, L. International Olympic Committee consensus statement on youth athletic development. Br J Sport Med 49:843-851, 2015. 
12. Brenner, JS. Overuse injuries, overtraining, and burnout in child and adolescent athletes. Pediatrics 119:1242-1245, 2007.

13. Brenner, JS, and Council on Sports Medicine and Fitness. Sport specialization and intensive training in young athletes. Pediatrics 138:e1-e8, 2016.

14. Butcher, J, Lindner, KJ, and Johns, DP. Withdrawal from competitive youth sport: a retrospective ten-year study. J Sports Behav 25:145-163, 2002.

15. Caldarone, G, Leglise, M, Giampietro, M, and Berlutti, G. Anthropometric measurements, body composition, biological maturation and growth predictions in young female gymnasts of high agonistic level. J Sports Med 26:263-273, 1986.

16. Coakley, J. Burnout among adolescent athletes - a personal failure or social problem? Sociol Sport J 9:271- 285, 1992.

17. Cobb, KL, Bachrach, LK, Sowers, M, Nieves, J, Greendale, GA, Kent, KK, Brown, BW Jr, Pettit, K, Harper, DM, and Kelsey, JL. The effect of oral contraceptives on bone mass and stress fractures in female runners. Med Sci Sports Exerc 239:14641473, 2007.

18. Collins, D, MacNamara, A, and McCarthy, N. Super champions, champions, and almosts: Important differences and commonalities on the rocky road. Fron Pysch 6:1 $11,2016$.

19. Côté, J, Lidor, R, and Hackfort, D. ISSP position stand: To sample or to specialize? Seven postulates about youth sport activities that lead to continued participation and elite performance, Int J Sport Ex Psych 7:7-17, 2009.

20. DiFiori, JP, Benjamin, HJ, Brenner, JS, Gregory, A, Jayanthi, N, Landry, GL, and Luke, A. Overuse injuries and burnout in youth sports: a position statement from the American Medical Society for Sports Medicine. Br J Sport Med 48:287-288, 2014.

21. Drinkwater, BL, Bruemner, $\mathrm{B}$, and Chesnut, $\mathrm{CH}$ III. Menstrual history as a determinant of current bone density in young athletes. J Am Med Ass 263:545-548, 1990.

22. Ducher, G, Turner, Al, Kukuljan, S, Pantano, KJ, Carlson, JL, Williams, NI, and De Souza, MJ. Obstacles in the optimization of bone health outcomes in the female athlete triad. Sports Med 41:587-607, 2011.

23. Emery, CA. Risk factors for injury in child and adolescent sport: a systematic review of the literature. Clin J Sport Med 13:256-268, 2003.

24. Erlandson, MC, Sherar, LB, Mirwald, RL, Maffulli, N, and Baxter-Jones, AD. Growth and maturation of adolescent female gymnasts, swimmers, and tennis players. Med Sci Sports Exerc 40:34-42, 2008.

25. Fredericson, M, Jennings, F, Beaulieu, C, and Matheson, GO. Stress fractures in athletes. Top Magn Reson Imaging 17:309-325, 2006.

26. Fuchs, RK, Bauer, JJ, and Snow, CM. Jumping improves hip and lumbar spine bone mass in pubescent children: a randomized controlled trial. J Bone Min Res 16:148156, 2001. 
27. Geithner, CA, Woynarowska, B, and Malina, RM. The adolescent spurt and sexual maturation in girls active and not active in sport. Ann Hum Biol 25:415-423, 1998.

28. Georgopoulos, NA, Markou, KB, Theodoropoulou, A, Paraskevopoulou, P, Varaki, L, Kazantzi, Z, Leglise, M, and Vagenakis, AG. Growth and pubertal development in elite female rhythmic gymnasts. J Clin Endocr Metab 84:4525-4530, 1999.

29. Georgopoulos, NA, Markou, KB, Theodoropoulou, A, Vagenakis, GA, Benardot, D, Leglise, ML, Dimopoulos, JCA, and Vagenakis, AG. Height velocity and skeletal maturation in elite female rhythmic gymnasts. J Clin Endocr Metab 86:5159-5164, 2001.

30. Georgopoulos, NA, Theodoropoulou, A, Roupas, NA, Rottstein, L, Tsekouras, A, Mylonas, P, Vagenakis, GA, Koukkou, E, Armeni, AK, Sakellaropoulos, G, Leglise, $\mathrm{ML}$, Vagenakis, AG, and Markou, KB. Growth velocity and final height in elite female rhythmic and artistic gymnasts. Hormones 11:61-69, 2012.

31. Gould, D, Tuffey, S, Udry, E, and Loehr, JE. Burnout in competitive junior tennis players: II. Qualitative analysis. Sport Psychol 10:341-366, 1996.

32. Gould, D. The professionalization of youth sports: it's time to act! Clin J Sport Med 19:81-82, 2009.

33. Güllich, A. Many roads lead to Rome - Developmental paths to Olympic gold in men's field hockey. Euro J Sport Sci 14:763-771, 2014.

34. Gustafsson, H, Kentta, G, Hassmen, $P$, and Lundqvist, C. Prevalence of burnout in competitive adolescent athletes. The Sports Psych 21:21-37, 2007.

35. Hall, R, Barber Foss, K, Hewett, TE, and Myer, GD. Sport specialization's association with an increased risk of developing anterior knee pain in adolescent female athletes. J Sport Rehabil 24:31-35, 2015.

36. Harrast, MA, and Colonno, D. Stress fractures in runners. Clin Sports Med 29:399416, 2010

37. Hawkins, D, and Metheny, J. Overuse injuries in youth sports: biomechanical considerations. Med Sci Sports Exerc 33:1701-1707.

38. Hewett, TE, Myer, GD, and Ford, KR. Decrease in neuromuscular control about the knee with maturation in female athletes. J Bone Joint Surg 86:1601-1608, 2004.

39. Housh, TJ, Thorland, WG, Johnson, GO, Tharp, GD, Cisar, CJ, Refsell, MJ, and Ansorge, CJ. Body composition variables as discriminators of sports participation of elite adolescent female athletes. Res Quar Ex Sport 55:302-305, 1984.

40. Hoch, AZ, Pajewski, NM, Moraski, L, Carrera, GF, Wilson, CR, Hoffmann, RG, Schimke, JE, and Gutterman, DD. Prevalence of the female athlete triad in high school athletes and sedentary students. Clin J Sports Med 19:421-428, 2009.

41. Horn, E, Gergen, N, and McGarry, KA. The female athlete triad. The Rhode Is Med J 97:18-21, 2014. 
42. Jayanthi, NA, LaBella, CR, Fischer, D, Pasulka, J, and Dugas, LR. Sportsspecialized intensive training and the risk of injury in young athletes: a clinical casecontrol study. Am J Sports Med 43:794-801, 2015.

43. Karlsson, MK, Nordqvist, A, and Karlsson, C. Physical activity increases bone mass during growth. Food Nutr Res 52: 1-10, 2008.

44. Kontos, AP, Feltz, DL, and Malina, RM. The perception of risk of injury in sports scale: confirming adolescent athletes' concerns about injury. J Sport Exerc Psychol 22:S12, 2000.

45. Le Bars, H, Gernigon, C, and Ninot, G. Personal and contextual determinants of elite young athletes' persistence or dropping out over time. Scand J Med Sci Sports 19:274-285, 2009.

46. Leone, M, Lariviere, G, and Comtois, AS. Discriminant analysis of anthropometric and biomotor variables among elite adolescent female athletes in four sports. $J$ Sports Sci 20:443-449, 2002.

47. Lindholm, C, Hirschberg, AL, Carlstrom, K, and von Schoultz, B. Altered adrenal steroid metabolism underlying hypercortisolism in female endurance athletes. Fertil Steril 63:1190-1194, 1995.

48. Liu, SL, and Lebrun, CM. Effect of oral contraceptives and hormone replacement therapy on BMD in premenopausal and perimenopausal women: a systematic review. Brit J Sport Med 40:11-24, 2006.

49. Lloyd, RS, and Oliver, JL. The youth physical development model: a new approach to long-term athletic development. Strength Cond J 34:61-72, 2012.

50. Lloyd, RS, Faigenbaum, AD, Stone, MH, Oliver, JL, Jeffreys, I, Moody, JA, Brewer, C, Pierce, KC, McCambridge, TM, Howard, R, Herrington, L, Hainline, B, Micheli, LJ, Jaques, R, Kraemer, WJ, McBride, MG, Best, TM, Chu, DA, Alvar, BA, and Myer, GD. Position statement on youth resistance training: the 2014 International Consensus. Brit J Sport Med 48:498-505, 2013.

51. Lloyd, RS, Oliver, JL, Faigenbaum, AD, Howard, R, De Ste Croix, MBA, Williams, CA, Best, TM, Alvar, BA, Micheli, LJ, Thomas, DP, Hatfield, DL, Cronin, JB, and Myer, GD. Long-term athletic development: part 1: A pathway for all youth. J Strength Cond Res 29:1439-1450, 2015.

52. Loucks, AB, Mortola, JF, Girton, L, and Yen, SS. Alterations in the hypothalamicpituitary-ovarian and the hypothalamic-pituitary-adrenal axes in athletic women. $J$ Clin Endocr Metab 68:402-411, 1989.

53. Loucks, AB, Verdun, M, and Heath, EM. Low energy availability, not stress of exercise, alters LH pulsatility in exercising women. J Appl Physiol 84:37-46, 1998.

54. Loucks, AB. Energy availability, not body fatness, regulates reproductive function in women. Exerc Sport Sci Rev 31:144-148, 2003. 
55. Mackay, HA, Petit, MA, Schutz, RW, Prior, JC, Barr, SI, and Khan, KM. Augmented trochanteric bone mineral density after modified physical education classes: a randomized school-based exercise intervention study in prepubescent and early pubescent children. J Pediatrics 136:156-162, 2000.

56. Maffulli, N, Baxter-Jones, AD, and Grieve, A. Long term sport involvement and sport injury rate in elite young athletes. Arch Dis Child 90:525-527, 2005.

57. Maïmoun, L, Georgopoulos, NA, and Sultan, C. Endocrine disorders in adolescent and young female athletes: impact on growth, menstrural cycles, and bone mass acquisition. J Clin Endocr Metab 99:4037-4050, 2014.

58. Malina, RM. Physical growth and biological maturation of young athletes. Exerc Sport Sci Rev 22:389-434, 1994.

59. Malina, RM. Early sport specialization: roots, effectiveness, risks. Curr Sports Med Rep, 9:364-371, 2010.

60. Malina, RM, Baxter-Jones, AD, Armstrong, N, Beunen, GP, Caine, D, Daly, RM, Lewis, RD, Rogol, $A D$, and Russell, $K$. Role of intensive training in the growth and maturation of artistic gymnasts. Sports Med 43:783-802, 2013.

61. Markou, KB, Mylonas, $P$, Theodoropoulou, A, Kontogiannis, A, Leglise, M, Vagenakis, AG, and Georgopoulos, NA. Bone acquisition in adolescent elite female and male artistic gymnasts. J Clin Endocr Metab 89:4383-4387, 2004.

62. Matos, N, Winsley, RJ, and Williams, CA. Prevalence of non-functional overreaching/overtraining in young English athletes. Med Sci Sport Exer 43:12871294, 2011.

63. Meeusen, R, Duclos, M, Foster, C, Fry, A, Gleeson, M, Nieman, D, Raglin, J, Rietjens, G, Steinacker, J, and Urhausen, A. Prevention, diagnosis and treatment of the overtraining syndrome: Joint consensus statement of the European College of Sport Science (ECSS) and the American College of Sports Medicine (ACSM). Euro $J$ Sport Sci 13:1-24, 2013.

64. Misra, M, Katzman, D, Miller, KK, Mendes, N, Snelgrove, D, Russell, M, Goldstein, MA, Ebrahimi, S, Clauss, L, Weigel, T, Mickley, D, Schoenfeld, DA, Herzog, DB, and Klibanski, A. Physiologic estrogen replacement increases bone density in adolescent girls with anorexia nervosa. J Bone Miner Res 26:2430-2438, 2011.

65. Moesch, K, Elbe, AM, Hauge, ML, and Wikman, JM. Late specialization: the key to success in centimeters, grams, or seconds (cgs) sports. Scan J Sports Med 21:e282e290, 2011.

66. Mostafavifar, AM, Best, TM, and Myer, GD. Early sport specialisation, does it lead to long-term problems? Br J Sport Med 47:1060-1061, 2013.

67. Mountjoy, M, Sundgot-Borgen, J, Burke, L, Carter, S, Constantini, N, Lebrun, C, Meyer, N, Sherman, R, Steffen, K, Budgett, R, and Ljungqvist, A. The IOC 
consensus statement: beyond the Female Athlete Triad-Relative Energy Deficiency in Sport (RED-S). Br J Sport Med 48:491-497, 2014.

68. Myer, GD, Jayanthi, N, DiFiori, JP, Faigenbaum, AD, Kiefer, AW, Logerstedt, D, and Micheli, LJ. Sports specialization, part I: does early sports specialization increase negative outcomes and reduce the opportunity for success in young athletes? Sports Health 7:437-442, 2015.

69. Myer, GD, Jayanthi, N, DiFiori, JP, Faigenbaum, AD, Kiefer, AW, Logerstedt, D, and Micheli, LJ. Sports specialization, part II: alternative solutions to early sport specialization in youth athletes. Sports Health 8:65-73, 2015.

70. Nattiv, A, Puffer, JC, Casper, J, and Dorey, F. Stress fracture risk factors, incidence and distribution: a 3-year prospective study in collegiate runner. Med Sci Sport Exer 5:S347, 2000.

71. Nattiv, A, Loucks, AB, Manore, MM, Sanborn, CF, Sundgot-Borgen, J, Warren, MP, and American College of Sports Medicine. American College of Sports Medicine position stand: the female triad. Med Sci Sport Exer 39:1867-1882, 2007.

72. Nichols, JF, Rauh, MJ, Lawson, MJ, Ji, M, and Barkai, HS Prevalence of the female athlete triad syndrome among high school athletes. Arch Paed Adoles Med 160:137142, 2006.

73. Nichols, JF, Rauh, MJ, Barrack, MT, Barkai, HS, and Pernick, Y. Disordered eating and menstrual irregularity in high school athletes in lean-build and nonlean-build sports. Int J Sport Nutr Exerc Metab 17:364-377, 2007.

74. Orio, F, Muscogiuri, G, Ascione, A, Marciano, F, Volpe, A, La Sala, G, Savastano, S, Colao, A, and Palomba, S. Effects of physical exercise on the female reproductive system. Minerva Endocrinol 38:305-319, 2013.

75. Peltenburg, AL, Erich, WBM, Bernink, MJE, Zonderland, ML, and Huisveld, IA. Biological maturation, body composition and growth of female gymnasts and control groups of schoolgirls and girls swimmers, aged 8 to 14 years: a cross-sectional survey of 1064 girls. Int J Sports Med 5:36-42, 1984.

76. Raglin, J, Sawamura, S, Alexiou, S, Hassmen, P, and Kentta, G. Training practices and staleness in 13-18-year-old swimmers: a cross-cultural study. Pediatr Exerc Sci 12:61-70, 2000.

77. Rauh, MJ, Nichols, JF, and Barrack, MT. Relationships among injury and disordered eating, menstrual dysfunction, and low bone mineral density in high school athletes: a prospective study. J Athl Train 45:243-252, 2010.

78. Read, PJ, Oliver, JL, De Ste Croix, MBA, Myer, GD, and Lloyd, RS. The scientific foundations and associated injury risks of early soccer specialisation, J Sports Sci, 34:2295-2302, 2016.

79. Reed, JL, Bowell, JL, Hill, BR, Williams, BA, De Souza, MJ, and Williams, NI. Exercising women with menstrual disturbances consume low energy dense foods and beverages. Appl Physiol Nutr Metab 36:382-394, 2011. 
80. Rees, T, Hardy, L, Güllich, A, Abernethy, B, Côté, J, Woodman, T, Montgomery, H, Laing, S, and Warr, C. The Great British medallists project: A review of current knowledge on the development of the world's best sporting talent. Sports Med 46:1041-1058, 2016.

81. Richardson, SO, Andersen, MB, and Morris, T. Overtraining Athletes: Personal Journeys in Sport. Champaign, IL: Human Kinetics, 170-181, 2008.

82. Robinson, TL, Snow-Harter, C, Taaffe, DR, Gillis, D, Shaw, J, and Marcus, R. Gymnasts exhibit higher bone mass than runners despite similar prevalence of amenorrhea and oligomenorrhea. J Bone Miner Res 10:26 -35, 1995.

83. Rowland, TW. Is the 'Athlete's Heart' arrhythmogenic? Sports Med 41:401-411, 2011.

84. Sabatier, JP, Guaydier-Souquières, G, Laroche, D, Benmalek, A, Fournier, L, Guillon-Metz, F, Delavenne, J, and Denis, AY. Bone mineral acquisition during adolescence and early adulthood: a study in 574 healthy females 10-24 years of age. Osteoporos Int 6:141-148, 1996.

85. Scofield, KL, and Hecht, S. Bone health in endurance athletes: runners, cyclists and swimmers. Curr Sports Med Rep 11:328-334, 2012.

86. Shuer, ML, and Dietrich, MS. Psychological effects of chronic injury in elite athletes. West J Med 166:104-109, 1997.

87. Smith, RE, Smoll, FL, and Cumming, SP. Effects of a motivational climate intervention for coaches on young athletes' sport performance anxiety. J Sport Exerc Psychol 29:39-59, 2007.

88. Sundgot-Borgen, J, and Larsen, S. Preoccupation with weight and menstrual function in female elite athletes. Scand J Med Sci Spor 3:156-163, 1993.

89. Sundgot-Borgen, J. Risk and trigger factors for the development of eating disorders in female elite athletes. Med Sci Sport Exer 26:414-419, 1994.

90. Thapar, A, Collishaw, S, Pine, DS, and Thaper, AK. Depression in adolescence. Lancet 379:1056-1067, 2012.

91. Theintz, GE, Howald, H, Allemann, Y, and Sizonenko, PC. Growth and pubertal development of young female gymnasts and swimmers: a correlation with parental data. Int J Sports Med 10:87-91, 1989.

92. Vanheest, JL, Rodgers, CD, Mahoney, CE, and De Souza, MJ. Ovarian suppression impairs sport performance in junior elite female swimmers. Med Sci Sport Exer 46:156-166, 2014.

93. Vescovi, JD, Jamal, SA, and De Souza, MJ. Strategies to reverse bone loss in women with functional hypothalamic amenorrhea: a systematic review of the literature. Osteoporos Int 19:465-478, 2008.

94. Warren, MP. The effects of exercise on pubertal progression and reproductive function in girls. J Clin Endocr Metab 51:1150-1157, 1980. 
95. Warren, MP, Brooks-Gunn, J, Fox, RP, Holderness, CC, Hyle, EP, Hamilton, WG, and Hamilton, L. Persistent osteopenia in ballet dancers with amenorrhea and delayed menarche despite hormone therapy: a longitudinal study. Fertil Steril 80:398-404, 2003.

96. Weiss Kelly, AK, Hecht, S, and Council on Sports Medicine and Fitness. The female athlete triad. Pediatrics 138:e1-e10, 2016.

97. Williams, NI, Helmreich, DL, Parfitt, DB, Caston-Balderrama, A, and Cameron, JL. Evidence for a causal role of low energy availability in the induction of menstrual cycle disturbances during strenuous exercise training. J Clin Endocr Metab 86:51845193, 2001.

98. Winsley, R, and Matos, N. Overtraining and elite young athletes. In: The Elite Young Athlete. Armstrong, N, and McManus, AM, eds. Vol. 56, Basel, Switzerland: Karger Medical and Scientific Publishers, 97-105, 2011. 